\title{
DEVELOPMENT OF THE EMERGY-GIS METHOD OF SELECTING AREAS FOR SPONGE-LIKE URBAN RECONSTRUCTION
}

\author{
LUO, Z. H..$^{1 *}$ ZHOU, Y. ${ }^{1}-$ CHEN, D. ${ }^{2}-$ ZHAO, H. Y. ${ }^{1}-$ ZHENG, Q. S. ${ }^{1}$ \\ ${ }^{I}$ College of Resources and Environmental Sciences, Nanjing Agricultural University \\ Nanjing 210095, Jiangsu Province, P. R. China \\ ${ }^{2}$ College of Agricultural Engineering, Hohai University \\ Nanjing 210098, Jiangsu Province, P. R. China \\ *Corresponding author \\ e-mail: lzhui@njau.edu.cn; phone: +86-25-8439-5815 \\ (Received 30 $0^{\text {th }}$ Dec 2018; accepted $12^{\text {th }}$ Feb 2019)
}

\begin{abstract}
The theory of sponge city has been attracting extensive attention in addressing urban waterrelated issues especially in China. We discussed on the emergy-GIS method of selecting areas for spongelike urban reconstruction in Shenzhen, with four main concerns including data source, neglecting the issue of urban waterlogging, potential inaccuracies in emergy calculations and indices in selecting key areas. The corresponding suggestions and solutions are developed including the rational selection of precipitation and anthropogenic heat, consideration of land use types in assumption of the first $50 \%$ of stormwater runoff, incorporation of areas with high risk of waterlogging, methods for emergy calculations of runoff and runoff pollution, scientific choice of indices and integration of local planning and actions. This study could help improve the emergy method integrated with GIS in the application of sponge city studies.
\end{abstract}

Keywords: sponge city, emergy, GIS, urban waterlogging, anthropogenic heat, runoff pollution

\section{Introduction}

The theory of Sponge City which is related to low impact development (LID) and green infrastructure (GI) has been attracting extensive attention in addressing waterrelated issues due to rapid urbanization (Jia et al., 2017; Xia et al., 2017; Jiang et al., 2018; Tang et al., 2018; Wang et al., 2018). Both its practice and theoretical research have become exciting topics across interdisciplinary fields for achieving urban sustainability especially in China (Li et al., 2017, 2018; Xu et al., 2018). Recently an important study was published with the title of an emergy-GIS method of selecting areas for sponge-like urban (Zhao et al., 2018). A comprehensive framework composed of stormwater indices and anthropogenic heat was employed to facilitate selection of key areas for sponge-like urban reconstruction based on the integration of emergy analysis and GIS models with a case study in Shenzhen. Zhao et al. (2018) also claimed that the proposed emergy-GIS framework could bridge the gap between empirical studies and standardize research to ensure that the results of the green infrastructure plan. Emergy evaluation integrated with GIS can certainly help the spatial analysis of sponge city planning (Odum, 1996; Pulselli, 2010; Chang and Huang, 2015; Chen et al., 2016; Wang et al., 2016). However, after extensive analysis of the modeling approach, we found four main issues with the study: (1) selection of time scale of data source; (2) neglecting the issue of urban waterlogging; (3) potential inaccuracies in emergy calculations of runoff and runoff pollution; and (4) choice of indices in selecting key 
areas. Therefore, we investigated these issues and provided the suggestions and solutions correspondingly. It will help develop the emergy method integrated with GIS in the application of sponge city studies.

\section{Main issues and solutions}

\section{Time scale of the data source}

Zhao et al. (2018) used the precipitation data from 2010 to assess the stormwater indices (stormwater runoff and runoff pollution). The year 2010 can be hydrologically characterized as an average to dry year. For reference, the annual precipitation data with the deviation from the long-time (1958-2017) average of $1935.8 \mathrm{~mm}$ is showed in Figure 1 (WRBS, 2018). Since precipitation is the dominant variable that determines runoff, and stormwater storage and runoff control are main tasks for sponge city construction, comparative analysis on the data from different typical hydrological years (wet, normal and dry) can help good understanding of the performance of sponge city construction (Jia et al., 2017; Jiang et al., 2018; Wang et al., 2018). Thus, it might be not sufficient to only use one year data from 2010, when is even a normal to dry year. It is recommended that the data from a wet year can be selected to enhance the analysis, such as 2013, 2014 or 2016 in Figure 1. Moreover, since Zhao et al. (2018) only used one precipitation value from the 2011 Shenzhen statistical yearbook, the temporal and spatial variability of precipitation was neglected (Tao et al., 2010; Ma et al., 2017; Luo et al., 2018). For reference, the monthly precipitation and the distribution of annual precipitation are showed in Figure 2 (MBSZM, 2011b). The annual precipitation data at typical hydrometric stations are presented in Figure 3 (WRBS, 2011), which can help improve the calculation of stormwater runoff on the use of one precipitation value by Zhao et al. (2018).

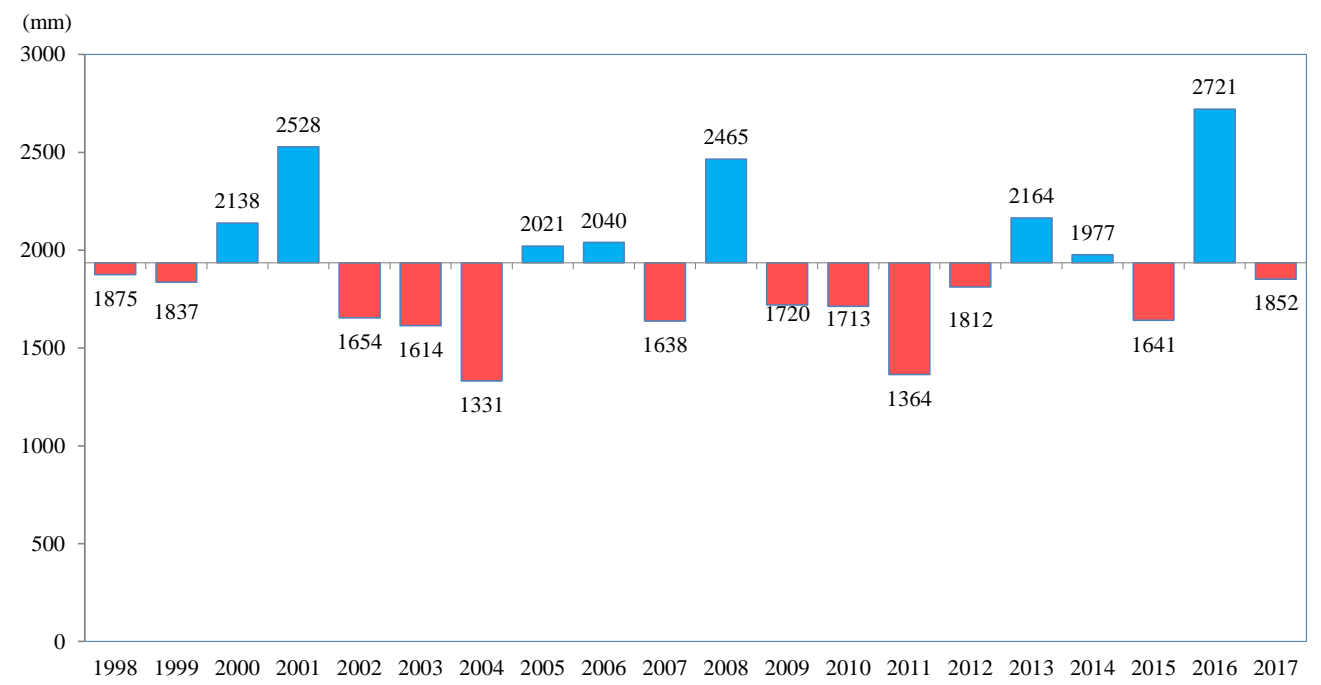

Figure 1. Annual precipitation data in Shenzhen (1998-2017) (WRBS, 2018)

Regarding the runoff pollution as the second indicator, Zhao et al. (2018) estimated the pollutant loadings using the first $50 \%$ of the stormwater runoff volume, which referred to a study by Qin et al. (2010) in Shenzhen. Yet, Qin et al. (2010) reported that 
impervious land use contributed significantly to first flush (the first proportion of the runoff volume containing the main proportion of the related pollutant load), whereas pervious land use had low or even zero first flush (Qin et al., 2010). Zhao et al. (2018) applied this assumption of the first $50 \%$ of stormwater runoff to all the land use types, which might cause overestimate of the runoff pollution. Thus, it is recommended that only impervious land use types can be considered into the estimation.

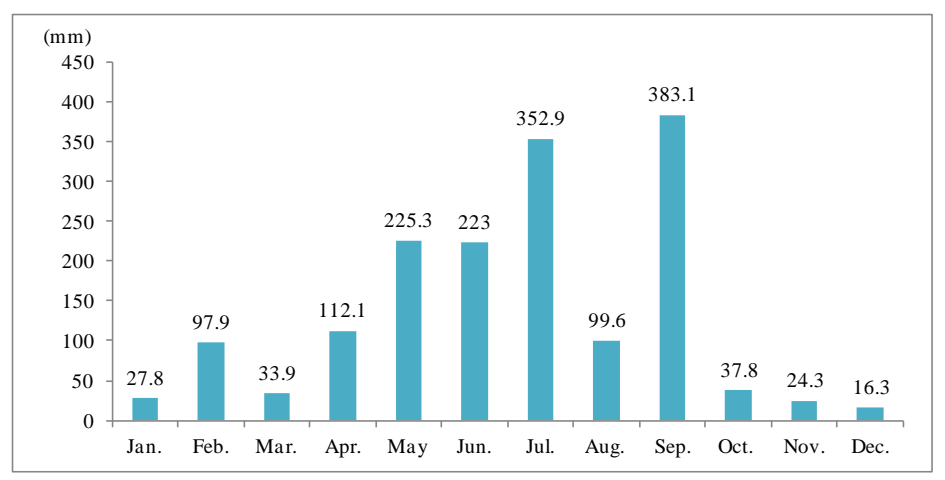

$\mathbf{a}$

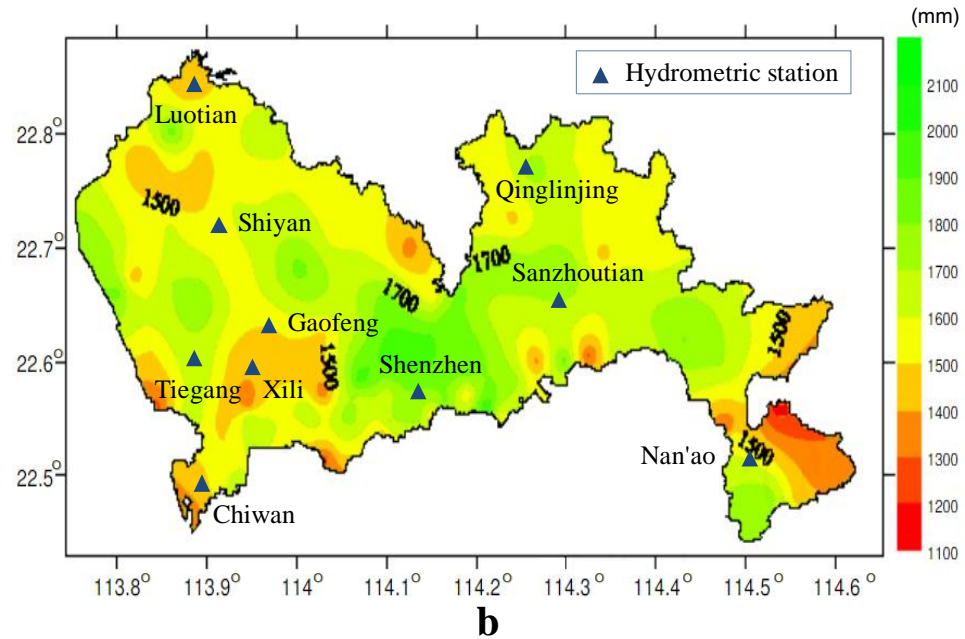

Figure 2. Temporal and spatial variability of precipitation in Shenzhen (2010) (MBSZM, 2011b). (a) Monthly precipitation in Shenzhen (2010). (b) Distribution of annual precipitation in Shenzhen (2010)

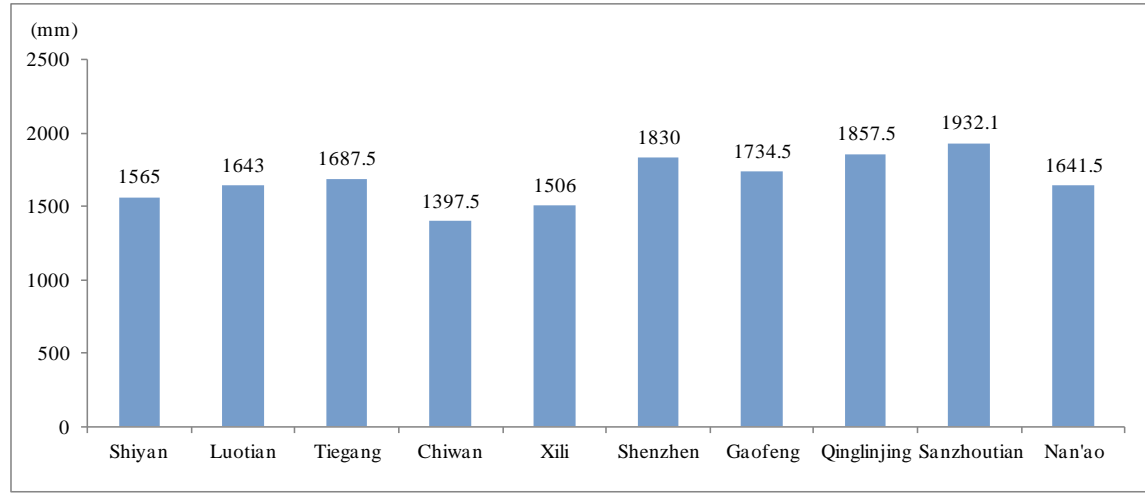

Figure 3. Annual precipitation data at typical hydrometric stations in Shenzhen (2010) (WRBS, 2011) 
Concerning the anthropogenic heat as the third indicator, Landsat-5 TM images and meteorological data (temperature) on December 23, 2010 were used by Zhao et al. (2018). The one-day data might be inconsistent with the whole year data for the precipitation and runoff analysis. Moreover, Zhao et al. (2018) did not interpret the representativeness of this day for the anthropogenic heat calculations. Yet, seasonspecific diurnal profiles of anthropogenic heating for cities had morning and evening peaks in summer and winter (Sailor and Lu, 2004). There are also typical characteristics of the temporal and spatial variation of anthropogenic heat flux in South China (Zhu et al., 2017). Anthropogenic heat has great impacts on the formation of urban heat island (UHI) effect, especially from June to August in Shenzhen (MBSZM, 2011a). Mitigation of the UHI effect has been considered as a major aim for sponge city construction, which was also a key indicator for the performance assessment of China's sponge city construction, issued by the Ministry of Housing and Urban-Rural Development of the People's Republic of China (MHURD) (MHURD, 2015a, 2018). The MHURD also claimed that the average daily data of temperature from June to September should be used to assess the mitigation of the UHI effect (MHURDa, 2015, 2018). However, the day of December 23 was not in this period. The maximum $\left(28^{\circ} \mathrm{C}\right)$, minimum $\left(20.9^{\circ} \mathrm{C}\right)$ and average $\left(24.5^{\circ} \mathrm{C}\right)$ temperatures on December 23 were different from the mean values from June to September $\left(35.3{ }^{\circ} \mathrm{C}, 22.1^{\circ} \mathrm{C}\right.$ and $28.6^{\circ} \mathrm{C}$, respectively). For reference, the monthly mean temperatures in 2010 are shown in Figure 4 (MBSZM, 2011b). Therefore, the proper date for the anthropogenic heat calculations can be a certain day from June to September, when has the same average temperature with that in this period, rather than December 23.

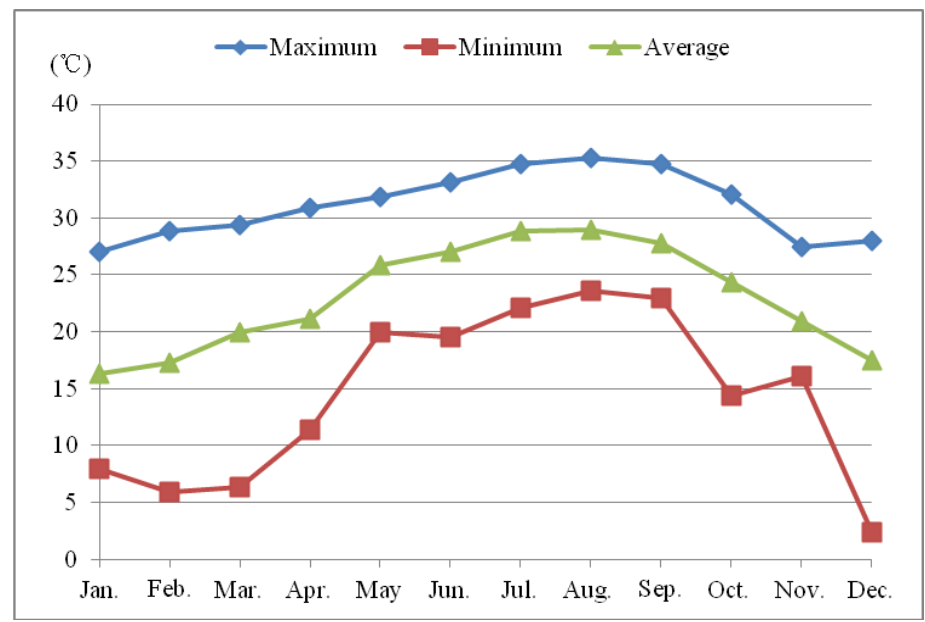

Figure 4. Monthly mean temperature in Shenzhen (2010) (MBSZM, 2011b)

\section{Neglect in the situation of urban waterlogging}

Mitigation and control of urban waterlogging and flooding is one of the foremost aims for China's Sponge City Construction pilot project programs. For instance, on September 30, 2015 the Chinese government has officially declared to build sponge cities to address urban waterlogging (Wang et al., 2018). It showed that China has been trying to turn its cities into "sponges" to better absorb rain following several fatal bouts of urban inundation in recent years. This target has also been written into two important official documents issued by the MHURD, which are the Performance Evaluation 
Indicators of China's Sponge City Demonstration (Pilot version) in 2015 (MHURD, 2015b) and the Assessment Standard for Sponge City (Discussion version) in 2018 (MHURD, 2018). In the past 60 years, Shenzhen has suffered as much as 111 times from flooding, water lodging and storm surge (Cai, 2017). As for the selection of key areas for sponge-like urban reconstruction, the situation of urban waterlogging in Shenzhen should be firstly incorporated into the evaluation system, including the spatiotemporal distribution, magnitude and frequency of waterlogging events. Investigation of urban waterlogging generally involves several factors, such as the extreme values of rainstorms, rainfall frequency of occurrence, land cover, drainage and runoff, urban drainage system capacity, and location of control structures (Xue et al., 2016; Ma et al., 2017; Sang and Yang, 2017; Lin et al., 2018). Neglecting urban waterlogging and solely using the 2010 precipitation data reduce the applicability of the selected areas for sponge city practices, as these regions could not reveal the extent of urban waterlogging events. In addition, the development of flood and waterlogging risk maps can help in improving the understanding of selecting key areas for sponge-like urban reconstruction (Zhang et al., 2005; Pandey et al., 2010). The Water Resources Bureau of Shenzhen Municipality has identified 446 areas with high risk of waterlogging in Shenzhen in 2015 (Fig. 5) (Cai, 2017). It is obvious that these waterlogging concerns have not been incorporated into the study of Zhao et al. (2018).

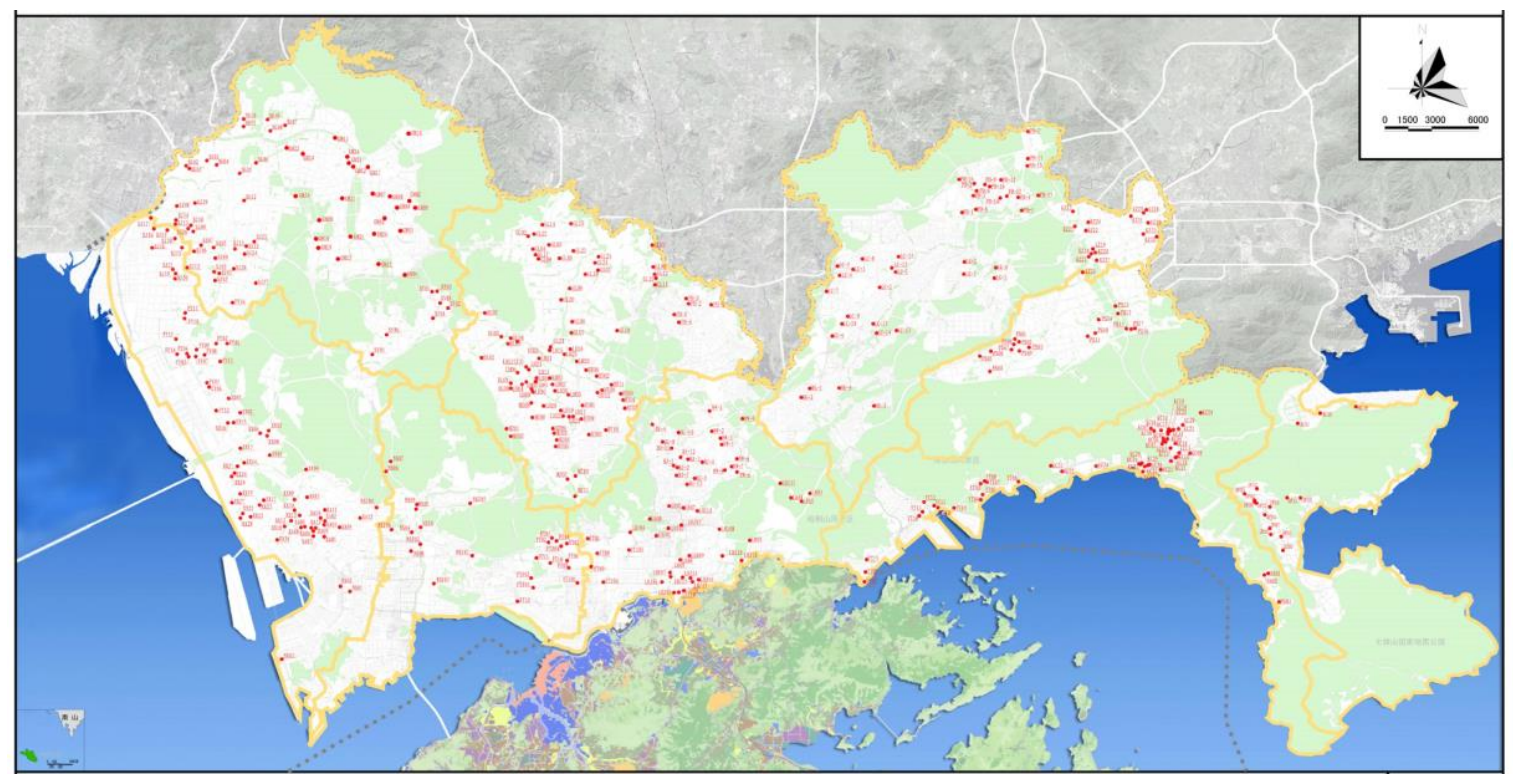

Figure 5. Locations with high-risk waterlogging in Shenzhen (Cai, 2017)

\section{Potential implications of the methods used for emergy calculations of runoff and runoff pollution}

Since Zhao et al. (2018) calculated the energy of runoff using the volume of runoff water, the water density and the Gibbs free energy, this energy was identified as the chemical potential energy. It appears like there is a misunderstanding in the underlying theory of chemical potential energy and geopotential energy (Kangas, 2002). As per the emergy theory, contributions of inland precipitation can be broken down into physical (runoff) and chemical (evapotranspiration) effects due to its gravitational and diffusive 
chemical potential energy relative to seawater (Odum, 1996; Buenfil, 2001; Chen et al., 2009; Mellino et al., 2014). Runoff represents a kind of elevated potential energy, rather than the chemical potential energy used by Zhao et al. (2018). The available energy associated with runoff can be a product of the mass flow rate, the gravitational constant, the elevation drop or head and the transformity of runoff geopotential (Kangas, 2002; Mellino et al., 2014). Since this geopotential is closely related to the elevation, the Digital Elevation Model (DEM) could be used (Wang et al., 2016). Thus, the equation of runoff energy can be used as Equation 1 (Mellino et al., 2014):

$$
\mathrm{En}_{\text {runoff }}=\mathrm{A} \times \rho_{\text {water }} \times \mathrm{R} \times \mathrm{g} \times \mathrm{h}
$$

where $A$ is the area in $\mathrm{m}^{2}, \rho_{\text {water }}$ is the water density $\left(1 \mathrm{E}+6 \mathrm{~g} / \mathrm{m}^{3}\right), R$ is the runoff in meters, $g$ is the gravitational constant $\left(9.81 \mathrm{~m} / \mathrm{s}^{2}\right)$ and $h$ is the vertical distance from the water level.

In addition, Zhao et al. (2018) claimed that the runoff analysis was based on the yearly precipitation data obtained from the 2011 Shenzhen Statistical Yearbook. Since this yearbook (Page 372) only presented a single dataset of the 2010 annual precipitation $(1634.0 \mathrm{~mm})$, it showed that Zhao et al. (2018) did not consider spatial and temporal variability in the distribution of precipitation in the runoff analysis. Moreover, according to the data from 1981 to 2010, the Meteorological Bureau of Shenzhen Municipality reported that the average annual evapotranspiration in Shenzhen was $1433 \mathrm{~mm}$, compared to the average annual precipitation of $1935.8 \mathrm{~mm}$. The evapotranspiration should not be ignored in the runoff calculation in the common water budget equation, as annual data was used by Zhao et al. (2018). Evapotranspiration map can be gained implementing Turc equation in GIS, which is an empirical equation with good results estimating evapotranspiration values for areas with annual mean temperatures. Thus, the runoff map can also be generated by the difference between precipitation map and evapotranspiration map (Mellino et al., 2014). Concerning the emergy calculation of runoff pollution, Zhao et al. (2018) obtained the emergy of Chemical Oxygen Demand (COD) by multiplying the energy of COD by the transformity of wastewater as adapted from Bjorklund et al. (2001). Yet, this transformity was based on an emergy analysis of household wastewater in a Swedish town, which was considered to be a by-product of the summation of all activities in terms of water used and food consumed including transport, processing and food storage (Björklund et al., 2001). Therefore, it is possible that the emergy might be orders of magnitude larger than the transformity of COD in natural runoff required by Zhao et al. (2018). Therefore, this potential overestimation of runoff pollution with differences in orders of magnitude can potentially change the integration of the three indices, which can further affect the selection of suitable areas. Due to lack of the proper transformity of COD, a potential solution can be direct calculation of the emergy of runoff pollution in terms of the emergy associated with dilution of COD pollutant to its environmental safety concentration, using Equations 2 and 3 (Li et al., 2013; Shao et al., 2017).

$$
\begin{gathered}
\mathrm{En}_{\text {runoff pollution }}=\rho_{\text {water }} \times\left(\mathrm{M}_{\mathrm{COD}} / \mathrm{C}_{\mathrm{COD}}\right)-\mathrm{M}_{\text {runoff pollution }} \\
\mathrm{Em}_{\text {runoff pollution }}=\mathrm{En}_{\text {runoff pollution }} \times \mathrm{G} \times \mathrm{UEV}_{\text {water }}
\end{gathered}
$$


where $M_{C O D}$ is the quantity of COD in grams, $C_{C O D}$ is the environmental safety concentration of COD in $\mathrm{g} / \mathrm{m}^{3}, M_{\text {runoff pollution }}$ is the total quantity of the runoff pollution in grams, $G$ is the Gibbs free energy $(4.82 \mathrm{~J} / \mathrm{g}), U E V_{\text {water }}$ is the transformity of surface water $\left(4.48 \times 10^{4} \mathrm{sej} / \mathrm{J}\right)$. According to China's environmental quality standard for surface water (GB 3838-2002), the environmental safety concentration of COD is $15 \mathrm{mg} / \mathrm{L}$ (EPB, 2002).

\section{Choice of indices in selecting key areas}

In order to select key areas for sponge-like urban reconstruction, Zhao et al. (2018) adopted three indices including stormwater runoff, runoff pollution and anthropogenic heat on the emergy-GIS method. In addition to the incorporation of water logging discussed in the previous section, techno-economic and institutional factors should also be considered in addition to the existing indices. From a practical perspective, the degree of demand, reconstruction costs, demonstration effects and importance of a certain region could have great impacts on whether this region can be selected as a priority area. These concerns have also been written into several official documents about China's sponge city construction plan. For instance, in January 2015, the MHRUD in conjunction with the Ministry of Finances and the Ministry of Water Resources issued a notice on selecting national-level pilot cities for sponge city construction with campaigning rules (Liu et al., 2017). These rules involved the positivity of local government, the rationality of construction demand and targets, the feasibility of construction projects, the innovation of investment and financing mode, and the integrity of supporting measures and infrastructure conditions (MHRUD, 2015). Therefore the three indices proposed by Zhao et al. (2018) might be incomplete for practical application in Shenzhen.

Based on the three indices, Zhao et al. (2018) presented emergy distribution maps and selection results with nine sub-districts. However, the validity of the results presented is questionable due to the aforementioned issues with data source, emergy calculation methods, and indices selection. Moreover, in November 2016 the Planning, Land and Resources Commission of Shenzhen Municipality (PLRCS) released two key planning documents on the sponge city construction in Shenzhen based on abundant data and materials (PLRCS, 2016a, b). The reports included several planning maps involving the spatial patterns, functional divisions and suitable areas (Figs. 6-8) (PLRCS, 2016a, b). Figure 6 presents main urban green spaces, wetland patches, major rivers, ecological corridors and ecological matrix spatial patterns, which can help identify the green cover spatial patterns of the sponge city construction in Shenzhen. Figure 7 presents the development and protection directions in different functional divisions. The suitable areas for the sponge city construction are shown in Figure 8, by identifying uncompleted urbanization areas and unsuitable areas (Karst distribution and slumping area, debris flow distribution area and landslide and slumping area). The Shenzhen Municipal Government selected 24 key areas with a total of $250.12 \mathrm{~km}^{2}$ for promoting the sponge city pilot construction (PLRCS, 2016b). Therefore, local policies and planning can have a significant influence on future sponge city construction in Shenzhen, however, the implications of these decisions have not been considered in Zhao et al. (2018). These figures and aforementioned information can be incorporated into the discussion section by Zhao et al. (2018), which help assess the validity of emergy distribution maps and improve the areas selection results for sponge-like urban reconstruction. 


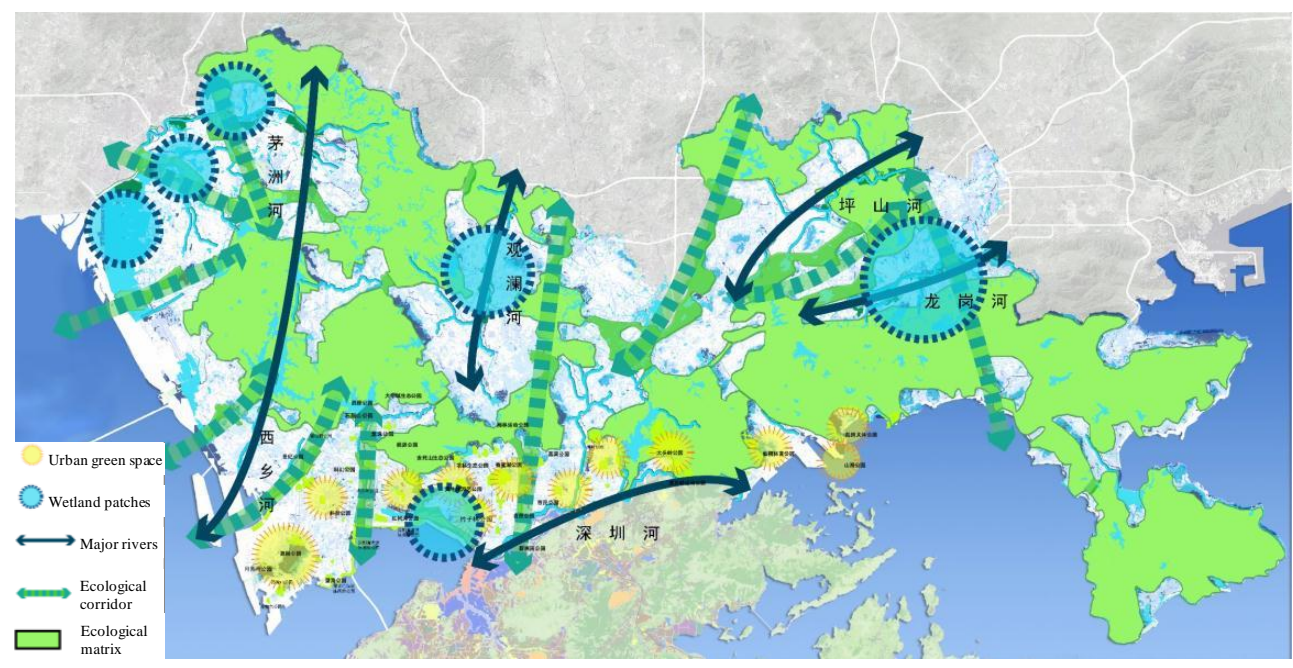

Figure 6. Spatial patterns of the sponge city construction in Shenzhen (PLRCS, 2016a)

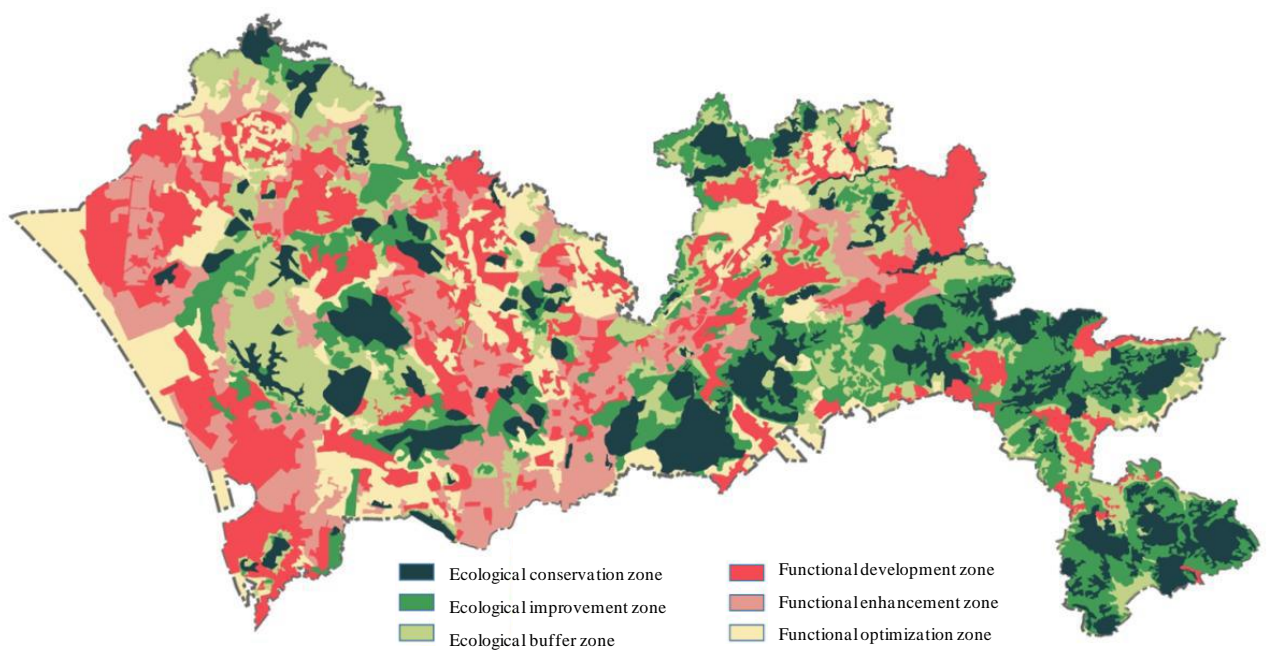

Figure 7. Functional divisions of the sponge city construction in Shenzhen (PLRCS, 2016a)

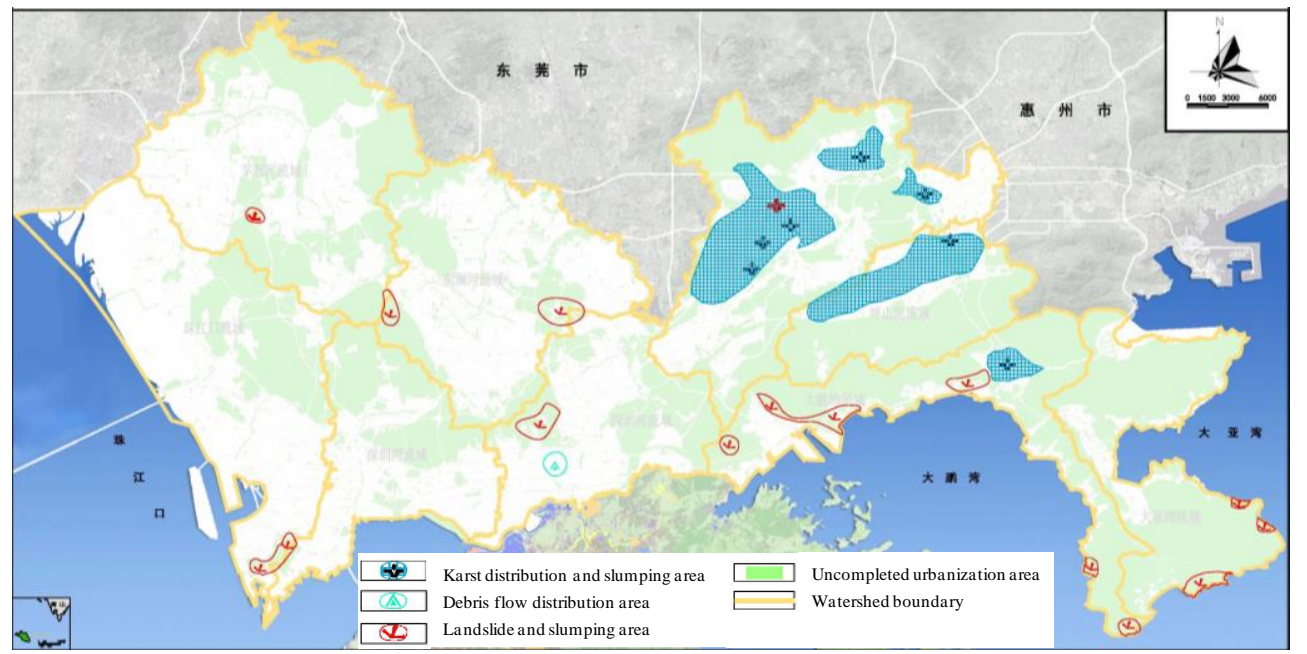

Figure 8. Suitable areas for the sponge city construction in Shenzhen (PLRCS, 2016a) 


\section{Conclusions}

The theory and practice of sponge city has been attracting extensive attention in addressing urban water-related issues especially in China. This paper focused on a study of the emergy-GIS method of selecting areas for sponge-like urban reconstruction in Shenzhen, with four main concerns including data source, neglecting the issue of urban waterlogging, potential inaccuracies in emergy calculations and indices in selecting key areas. As per the detailed discussion provided in the previous sections, there are four main conclusions that can help improve the analysis further and develop the emergy method integrated with GIS in the application of sponge city studies. These are summarized below:

(1) The analysis of selecting areas for sponge-like urban reconstruction based on an emergy-GIS method needs to be modified due to the improper time scale of data source and inconsistencies in the data itself. The main solutions include the rational selection of precipitation data, consideration of land use types in assumption of the first $50 \%$ of stormwater runoff and date selection for the anthropogenic heat calculations.

(2) Since mitigating urban waterlogging is the primary objective for sponge city construction, the spatio-temporal distribution, magnitude, and frequency of waterlogging events in Shenzhen should not be neglected and need to be revaluated while considering these parameters. Incorporation of areas with high risk of waterlogging is needed for the selection of key areas for sponge city construction.

(3) The methods used for emergy calculations of runoff and runoff pollution ignore runoff geopotential, spatio-temporal rainfall distribution, and evapotranspiration, which can potentially weaken the reliability of the emergy distribution maps. The theory and equations which we presened above can improve the methods for emergy calculations of runoff and runoff pollution.

(4) The existing indices for selecting key areas for sponge city construction should also consider techno-economic and institutional factors such as local planning and actions. This can help in providing a more robust spatial-discretization of key areas.

Acknowledgements. This study is supported by a Project Funded by the Priority Academic Program Development of Jiangsu Higher Education Institutions (PAPD) and Australian Research Council for Discovery Project Grant (DP170104138). We thank the anonymous reviewers and the editors for their constructive comments, which helped us to improve the manuscript.

\section{REFERENCES}

[1] Björklund, J., Geber, U., Rydberg, T. (2001): Emergy analysis of municipal wastewater treatment and generation of electricity by digestion of sewage sludge. - Resources, Conservation and Recycling 31: 293-316.

[2] Buenfil, A. A. (2001): Emergy Evaluation of Water. - Department of Environmental Engineering Sciences, University of Florida, Gainesville, USA.

[3] Cai, H. (2017): Decoding Sponge City in Shenzhen: Resilience Program or Growth Policy? - Massachusetts Institute of Technology. Cambridge, MA.

[4] Chang, L., Huang, S. (2015): Assessing urban flooding vulnerability with an emergy approach. - Landscape Urban Plan 143: 11-24.

[5] Chen, D., Chen, J., Luo, Z. H., Lv, Z. W. (2009): Emergy evaluation of the natural value of water resources in Chinese rivers. - Environ Manage 44: 288-297. 
[6] Chen, D., Liu, Z., Luo, Z. H., Webber, M., Chen, J. (2016): Bibliometric and visualized analysis of emergy research. - Ecol Eng 90: 285-293.

[7] EPB (2002): Environmental Quality Standards for Surface Water (GB 3838-2002). Ministry of Environmental Protection of the People's Republic of China. Environmental Protection Bureau, Beijing.

[8] Jia, H., Wang, Z., Zhen, X., Clar, M., Shaw, L. Y. (2017): China's sponge city construction: A discussion on technical approaches. - Frontiers of Environmental Science $\&$ Engineering 11: 18.

[9] Jiang, Y., Zevenbergen, C., Ma, Y. (2018): Urban pluvial flooding and stormwater management: A contemporary review of China's challenges and "sponge cities" strategy. - Environ Sci Policy 80: 132-143.

[10] Kangas, P. (2002): Handbook of Emergy Evaluation. Folio\# 5, Emergy of Landforms. Center for Environmental Policy, Environmental Engineering Sciences, University of Florida, Gainesville, FL.

[11] Li, H., Ding, L., Ren, M., Li, C., Wang, H. (2017): Sponge city construction in China: a survey of the challenges and opportunities. - Water 9: 594.

[12] Li, M., Zhang, X., Li, Y., Zhang, H., Zhao, M., Deng, S. (2013): Environmental impacts of sewage treatment system based on emergy analysis. - J Appl Ecol 24: 488-496.

[13] Li, Z., Xu, S., Yao, L. (2018): A systematic literature mining of sponge city: trends, foci and challenges standing ahead. - Sustainability 10: 1182.

[14] Lin, T., Liu, X., Song, J., Zhang, G., Jia, Y., Tu, Z., Zheng, Z., Liu, C. (2018): Urban waterlogging risk assessment based on internet open data: a case study in China. Habitat Int 71: 88-96.

[15] Liu, H., Jia, Y., Niu, C. (2017): "Sponge city" concept helps solve China's urban water problems. - Environmental Earth Sciences 76: 473.

[16] Luo, C., Liu, Y., Zhu, X., Hanxiu, F. U. (2018): Tempo-spatial changes of precipitation of Shenzhen in last 57 years. - Hydro-Science and Engineering 3(24): 24-31.

[17] Ma, Y., Lai, C., Xi, S., Chen, X., Deng, J. (2017): Analysis and determination of extreme precipitation threshold in highly urbanized areas of Southern China: A case from Shenzhen. - Journal of Water Resources \& Water Engineering 28(2): 79-84. (In Chinese)

[18] MBSZM (2011a): Monitoring bulletin on urban heat island effect in Shenzhen (2010). Meteorological Bureau of Shenzhen Municipality. http://www.szmb.gov.cn/qixiangfuwu/qihoufuwu/qihouguanceyupinggu/chengshiredaojia nce/201804/t20180424_11783221.htm (accessed 10.18).

[19] MBSZM (2011b): Shenzhen climate bulletin (2010). - Meteorological Bureau of Shenzhen Municipality. https://wenku.baidu.com/view/6b4103fa284ac850ad0242e4.html (accessed 10.18).

[20] Mellino, S., Ripa, M., Zucaro, A., Ulgiati, S. (2014): An emergy-GIS approach to the evaluation of renewable resource flows: a case study of Campania Region, Italy. - Ecol Model 271: 103-112.

[21] MHRUD (2015a): A notice on selecting national-level pilot cities for sponge city construction. - Ministry of Housing and Urban-Rural Development of the People's Republic of China. http://jjs.mof.gov.cn/zhengwuxinxi/tongzhigonggao/201501/t20150121_1182677.html (accessed 08.18).

[22] MHURD (2015b): Performance Evaluation Indicators of China's Sponge City Demonstration (Pilot version) in 2015. - Ministry of Housing and Urban-Rural Development of the People's Republic of China. http://www.mohurd.gov.cn/wjfb/201507/t20150715_222947.html (accessed 08.18).

[23] MHURD (2018): Assessment standard for sponge city (Discussion version) in 2018. Ministry of Housing and Urban-Rural Development of the People's Republic of China. http://www.mohurd.gov.cn/wjfb/201507/t20150715_222947.html (accessed 08.18). 
[24] Odum, H. T. (1996): Environmental Accounting: Emergy and Environmental Decision Making. - John Wiley \& Sons, New York.

[25] Pandey, A., Singh, S. K., Nathawat, M. (2010): Waterlogging and flood hazards vulnerability and risk assessment in Indo Gangetic plain. - Natural Hazards 55: 273-289.

[26] PLRCS (2016a): Planning key points and review details about the sponge city construction in Shenzhen. http://www.sz.gov.cn/cn/xxgk/zfxxgj/tzgg/201703/P020170314410812720232.pdf (accessed 08.18).

[27] PLRCS (2016b): Special planning and implementation schemes about the sponge city construction in Shenzhen. http://www.szwrb.gov.cn/ztzl_78021/bmzdgz/hmcsjs/zhyw/201711/P0201711216314701 64343.pdf (accessed 08.18).

[28] Pulselli, R. M. (2010): Integrating emergy evaluation and geographic information systems for monitoring resource use in the Abruzzo region (Italy). - Journal of Environmental Management 91: 2349-2357.

[29] Qin, H. P., Khu, S. T., Yu, X. Y. (2010): Spatial variations of storm runoff pollution and their correlation with land-use in a rapidly urbanizing catchment in China. - Sci Total Envir 408: 4613-4623.

[30] Sailor, D. J., Lu, L. (2004): A top-down methodology for developing diurnal and seasonal anthropogenic heating profiles for urban areas. - Atmos Environ 38: 2737-2748.

[31] Sang, Y., Yang, M. (2017): Urban waterlogs control in China: more effective strategies and actions are needed. - Natural Hazards 85: 1291-1294.

[32] Shao, S., Mu, H., Yang, F., Zhang, Y., Li, J. (2017): Application of emergy analysis to the sustainability evaluation of municipal wastewater treatment plants. - Sustainability 9: 8.

[33] Tang, Y. T., Chan, F. K. S., O’Donnell, E. C., Griffiths, J., Lau, L., Higgitt, D., Thorne, C. R. (2018): Aligning ancient and modern approaches to sustainable urban water management in China: Ningbo as a "Blue-Green City" in the "Sponge City" campaign. Journal of Flood Risk Management: e12451.

[34] Tao, Y., Shao, Q. X., Hao, Z. C., Xi, C., Zhang, Z. X., Xu, C. Y., Sun, L. M. (2010): Regional frequency analysis and spatio-temporal pattern characterization of rainfall extremes in the Pearl River Basin, China. - J Hydrol 380: 386-405.

[35] Wang, C., Zhang, S., Yan, W., Wang, R., Liu, J., Wang, Y. (2016): Evaluating renewable natural resources flow and net primary productivity with a GIS-Emergy approach: A case study of Hokkaido, Japan. - Scientific Reports 6: 37552.

[36] Wang, H., Mei, C., Liu, J., Shao, W. (2018): A new strategy for integrated urban water management in China: Sponge city. - Science China Technological Sciences: 317-329.

[37] WRBS (2011): Shenzhen Water Resources Bulletin (2010). - Water Resources Bureau of Shenzhen Municipality. http://www.szwrb.gov.cn/xxgk_73214/zfxxgkml/szswgk/tjsj/szygb/201711/P0201711086 46661981407.pdf (accessed 10.18).

[38] WRBS (2018): Shenzhen Water Resources Bulletin (2017). - Water Resources Bureau of Shenzhen Municipality. http://www.szwrb.gov.cn/xxgk_73214/zfxxgkml/szswgk/tjsj/szygb/201808/P0201808104 02899147240.pdf (accessed 08.18).

[39] Xia, J., Zhang, Y., Xiong, L., He, S., Wang, L., Yu, Z. (2017): Opportunities and challenges of the Sponge City construction related to urban water issues in China. Science China Earth Sciences 60: 652-658.

[40] Xu, Y., Shen, S., Lai, Y., Zhou, A. (2018): Design of Sponge City: lessons learnt from an ancient drainage system in Ganzhou, China. - J Hydrol 563: 900-908.

[41] Xue, F., Huang, M., Wang, W., Zou, L. (2016): Numerical simulation of urban waterlogging based on Floodarea model. - Advances in Meteorology 2016(1): 1-9. 
[42] Zhang, X., An, R., Zhang, W. (2005): Development of flood and waterlogging risk map for Shanghai City. - J Hohai Univ (Nat Sci) 33: 251-254.

[43] Zhao, Y., Yang, M., Ni, H. (2018): An emergy-GIS method of selecting areas for spongelike urban reconstruction. - J Hydrol 264: 640-650.

[44] Zhu, K., Wei, Z., Min, X., Zhu, X., Li, M., Wen, F. (2017): Characteristics of the Temporal and Spatial Variation of Anthropogenic Heat Flux in South China. - Journal of Ecology \& Rural Environment 33: 201-206. 